\title{
NETFLIX: A CASE STUDY ON INTERNATIONAL BUSINESS STRATEGY DEVELOPMENT
}

\author{
Irina V. Onyusheva \\ Ann S. Baker
}

Stamford International University, Bangkok, Thailand

This paper aims to discover Netflix, Inc., as a successful global organization exploring the possible motives for international engagements. Key aspects in the development of Netflix's international business strategy are considered, particularly focusing on its entry modes into various markets and its features of online streaming services. The given research reflects on the current market industry situation. The authors are studying the case of Netflix in the context of its developing international business strategy. In terms of research methods, we have implemented SWOT, PESTEL, causes and consequences analysis, and also expert assessment.

Risk identification, risk assessment and risk management analysis have been incorporated to detect significant business environmental factors for the company in question. On the basis of risk management methods, we have also considered possible risk management and control strategies along with the author's own recommendations on how to maintain the company's position as the global leading online streaming brand at the international market.

Keywords: international business; business strategy; business development; risk management; Netflix

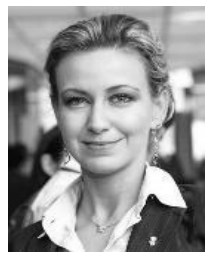

STAMFORD UNIVERSITY Unleash Your Potential

\section{Irina V. Onyusheva}

Dr., Prof., Stamford International University, Bangkok, Thailand.

Research interests: strategic management; economic competitiveness on micro- and macrolevels; human capital development; knowledge economy; knowledge management; project management.

E-mail: dr.irina.onyusheva@gmail.com

\section{Ann S. Baker}

MBA, Stamford International University, Bangkok, Thailand.

Research interests: international business management; strategic management; risk management.

E-mail: ann.s.baker@gmail.com 


\section{Introduction}

Netflix has started as an online movie rentals business back in 1997, providing services in the United States only.

Today, it has become one of the world's leading streaming entertainment services with 183 mln paid memberships in over 190 countries, providing TV series, documentaries and feature films across a wide variety of genres and languages (Netflix, 2020). Its online streaming services allow members to watch as much content as they want, accessing content anywhere and anytime on any internet-connected device. In addition to partnering with content providers to license streaming rights for a variety of TV shows and movies, the company also produces its in-house, original content (Netflix, 2020).

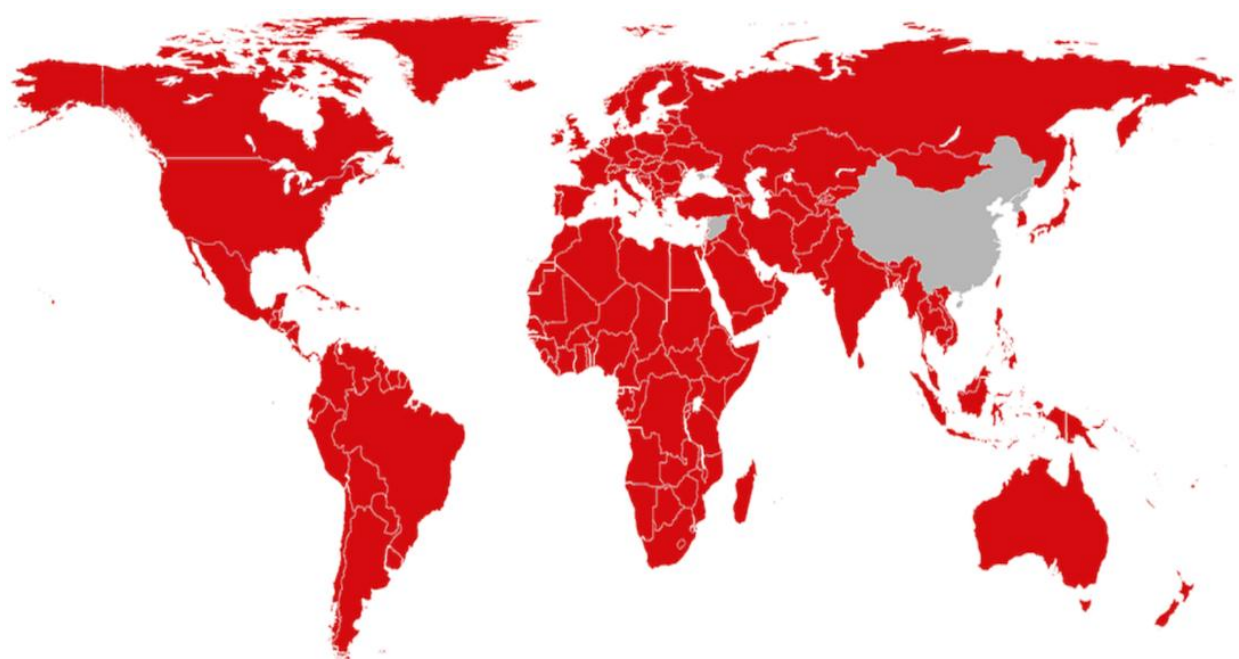

Figure 1 - Netflix's Global Presence

(Source: https://www.netflix.com)

Netflix is a publicly listed company that went public on May 23, 2002, with an initial public offering (IPO) price of $\$ 15$ per share. It was the best-performing stock in the S\&P 500 from 2010 through 2019 (Investopedia, 2020).

Netflix has been ranked 47th on Forbes list of "Top 100 Digital Companies of 2019", it has been also ranked 38th on "World's Most Valuable Brands 2019" and 431st on "GLOBAL 2000: The World's Largest Public Companies" (Forbes). Although its services reach members across the globe, Netflix is headquartered in Los Gatos, CA, and it also has 19 office locations across other 14 countries (Craft, 2020).

Netflix is part of the video streaming industry. The global video streaming market size was valued at $\$ 42.6 \mathrm{~B}$ back in 2019 . The industry is surely expected to continue to grow, in line with consistent innovations in technology to improve streaming quality and especially considering the two years of the ongoing pandemic.

As of 2019, over 100 streaming services were competing with each other in this industry (Emster, 2019). 


\section{NETFLIX: A CASE STUDY ON INTERNATIONAL}

The goals of this study are:

- explore the company's background and the industrial context;

- $\quad$ understand the company's motives for international engagements and its expansion strategy;

- $\quad$ analyze the entry modes into international markets;

- $\quad$ assess the business environment using SWOT and PESTEL analyses;

- identify and assess risks for the company entering various international markets;

- provide own recommendations concerning the expansion into new markets.

\section{International Expansion}

Netflix is a truly global enterprise. As of 2020, it had operations in over 190 countries, and more than half of its 183 mln subscribers live outside of the US (Netflix, 2020). In the second quarter of 2019, subscriptions from the members outside the US contributed to over half of the company's revenue (Reyes, 2019).

This is illustrated below in Fig. 2. Noteworthy, oly ten years ago, back in 2010, Netflix was available only in the United States. By 2017, the company had expanded to over 190 countries (Netflix, n.d.).

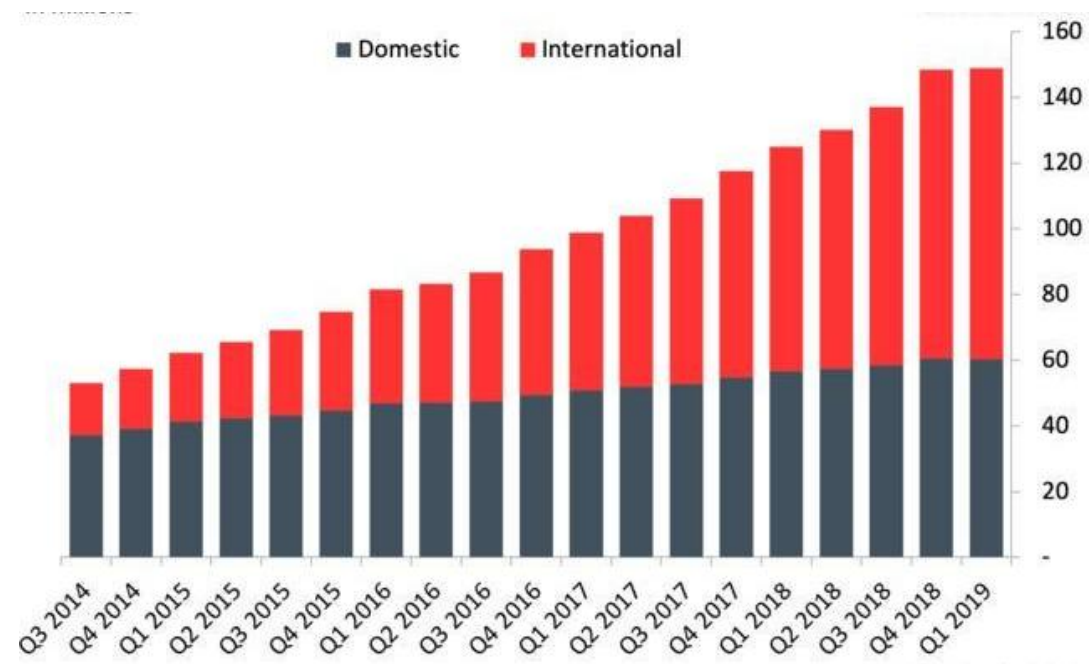

Figure 2 - Netflix Domestic vs. International Subscribers (in mln)

(Source: https://www.businessinsider.com/netflix-focuses-on-public-policy-strategy-abroad-2019-8)

\section{Motivations for International Expansion}

According to Netflix's chief executive, Reed Hastings, the company's global expansion was strategically motivated to offset the financial impact of slowing down growth in the United States. By growing the company's global markets, the aim was to help Netflix reach its target profits, which would allow the company to reinvest in its service as well as develop and license more content (Steel, 2015).

Before it adopted an international expansion strategy, Netflix reported subscriber growth of around $2.4 \mathrm{mln}$ members per year. 
The subscription growth increased to an average of $7 \mathrm{mln}$ subscribers per year following its initial phase of expansion into the first group of markets, including Canada, Europe, and Latin America (Smith, 2014).

The motivations behind its international expansion was to gain access to new customer bases and remain the leader in the industry, especially as the U.S. subscriptions started to drop under the increasing domestic competition. By capturing more market segments and a larger market share, the international expansion also brought in more revenue for the company.

\section{Global Expansion Strategy}

Netflix took a phased approach to its global expansion strategy. It first started with the countries that were relatively close geographically/physically and also the markets with similarities to the U.S. For example, its initial international expansion was back in 2010 to Canada, which is geographically very close to and shares many similarities with the United States (Brennan, 2018). By doing so, the company was able to learn more about internationalization capabilities in locations outside the U.S.

At the second phase of its expansion, Netflix rolled out its services to another 43 countries, mostly in Latin America and Western Europe (Izquierdo-Castillo, 2015). This helped the company to continue learning about localization and partnerships with local companies and stakeholders. It also allowed Netflix to collect data and study different consumer behaviors within different markets.

During the third and final phase, Netflix ramped up entry into the remaining markets, to bring it to 190 countries. It was able to use everything it had learned during the previous phases, where it had gained expertise in the content people prefer, the marketing they respond to, and how the company needed to organize itself overall (Brennan, 2018).

Netflix adopts a transnational approach: the company launches the same basic concept of the product globally, but also localizes content and marketing efforts to respond to the local consumers.

The basic concept of its product is the low-cost monthly subscription for unlimited content viewing, and the user interface of the product - this stays the same for all the markets. On the localization part, Netflix has its international content translated into local languages and local content created specifically for certain markets (Brooks, 2019). For example, in South Korea, Netflix entered into a strategic partnership with Studio Dragon, a leading production studio, to produce original content, which would attract South Korean consumers specifically (Netflix, 2019). It also launched the "Top 10 list" feature, which allows viewers to see shows that are trending in their location.

Modes of Entry into Foreign Markets. Netflix has a hybrid entry mode which differs from market to market. While the company exports much of its US-centric content, it also licenses its content to local market players, giving them the right to show Netflix's content. The company partners with key local companies, such as cell phone and cable operators, to make its content available as part of their existing video-on-demand offering (Brennan, 2018).

An example of licensing is Netflix's entry approach to China. Netflix does not currently operate as a company or service provider in China. It has struggled with entering this market since China has strict data and censorship regulations. 


\section{NETFLIX: A CASE STUDY ON INTERNATIONAL}

However, it introduced its original content at Chinese market via the licensing deal with one of China's largest video streaming services, iQiyi.com.

Another example: as the company prepared to enter Japan, it partnered with Japanese talent agency Yoshimoto Kogyo to produce exclusive local shows. The partnership involved funding by Netflix in exchange for exclusive streaming rights to the shows for a certain period of time (Schilling, 2015).

In Thailand, Netflix partnered with Thai mobile network AIS (Advanced Info Service), allowing AIS to offer its customers exclusive entertainment (The Nation, 2017), while simultaneously promoting Netflix's international expansion.

\section{The SWOT Analysis}

\section{Strengths}

Netflix's strengths include its ability to benefit from the first-mover advantage. As a pioneer in the streaming video-on-demand field, Netflix has succeeded in experiencing exceptional growth over the past ten years, to reach over 150 million global viewers (Saurel, 2019). It also has more subscribers worldwide than all other streaming services combined (Penamatsa, 2018). The company's huge volume of operations allows it to benefit from the economies of scale; as its subscriber base increases, the company benefits from lower cost per unit. It creates original content that attracts millions of viewers (Kolbin, 2019) and cannot be imitated by the competitors.

\section{Weaknesses}

Its weaknesses, however, include heavy dependence on the providers that determine customers' connectivity speed, which is a critical factor influencing customer satisfaction with Netflix's services (Rivera, 2019). Therefore, if an Internet connection is not present in a certain location, Netflix is not able to provide its services there. While its original content attracts viewers, the production of movies and series has rather high costs, which have driven up Netflix's operational costs (Bowman, 2017). Furthermore, the business model is easy to copy, which has been clearly illustrated by the fast rise of direct competitors.

\section{Opportunities}

Opportunities include further international expansion. For example, Netflix has not penetrated China just yet, which would be a huge opportunity given the market size. Netflix is still advertisement free, but it could explore a new revenue stream from advertisements. There is a great potential for revenues there, given that the TV advertising industry is worth over $\$ 70$ bln these days (McBride, 2019). In addition, there are opportunities to increase and strengthen partnerships with both content providers and producers globally.

Threats. Threats in the context of international expansion are different regulations in different countries that could prevent Netflix from entering the market or limit its business activities. For example, the EU has introduced a new rule for services like Netflix, saying that at least $30 \%$ of the offering would need to be made up of European production (Reyes, 2019). Furthermore, there is increased competition from both global and local players, with over 100 streaming services being available, as of 2019 (Emster, 2019). Furthermore, because Netflix operates internationally, revenues from international markets are affected by the fluctuations in exchange rates (Penamatsa, 2018). 


\section{PESTEL Analysis}

Political factors. Since Netflix is a US-based company, international political and economic relationships with other countries may have an impact on where the company expands. It also needs to consider politics when it is looking to launch content into certain markets. For example, when it promoted the show "Narcos," many people in Colombia were offended because they saw it as Netflix promoting the drug lord Pablo Escobar who had damaged their country and culture (Brodzinsky, 2015).

Economic factors. Economic factors include, inter alia, fluctuating exchange rates. As Netflix is operating in many countries and currencies across the world, adverse foreign exchange rate fluctuations could impact its earnings (Pelts, 2016). Economic growth at different markets is also a factor directly impacting the purchasing power; an increase in disposable income would eventually lead to increased spending on entertainment (Penamatsa, 2018).

Social factors. Key factors include consumer demographics and consumer preferences, as both have direct impacts on product offerings. Netflix needs to study and understand its audience to tailor its marketing efforts and content and thus attract viewers from different backgrounds and cultures.

Technological factors. Technological factors are perhaps the most important ones as Netflix and the streaming industry as a whole are heavily dependent on them. These factors include internet coverage, speed, and capacity, all having a direct impact on viewers' accessibility and streaming quality. Therefore, Netflix needs to consider the technological advancements of the different markets it enters. However, with the growth and expansion of the internet in general, including accessibility on phones, tablets, and smart televisions (Brennan, 2016), this is a promoting factor for Netflix.

Environmental factors. Netflix has the opportunity to play a larger part in contributing to environmental preservation by sourcing more renewable energy to offset its carbon footprint. Although it does not produce physical products, it does indirectly produce carbon dioxide by using energy to run the servers. Many tech companies are switching to this trend. For example, larger tech companies, such as Apple, Facebook, and Google, continue to lead efforts to build an Internet that is renewably powered (Pomerantz, 2012).

Legal factors. Primary factors include adhering to government regulations on censorship across different countries (Pelts, 2016). This has a direct impact on the content Netflix can stream in different markets, and also the extent to which it needs to edit its content. Furthermore, because Netflix produces and licenses a lot of content, it must also consider copyright and intellectual property rights legislation. As Netflix is operating in many countries, it must face a diverse set of national regulatory restrictions, such as those that limit what content can be made available in local markets (Brennan, 2016); therefore, it must invest in the resources that ensure compliance with regulatory bodies in each market.

Risk Management. Business risk is the degree of exposure a company or an organization has to the factor(s) that will lower its profits or lead it to fail (Kenton, 2019). This includes anything that poses a threat to a company's ability to achieve its targets and/or financial goals. When companies engage in international business activity, they take on additional risks along with the opportunities (Beers, 2019). The section below is devoted to the risks from the internationalization of Netflix as well as potential measures for their control and mitigation. 


\section{NETFLIX: A CASE STUDY ON INTERNATIONAL}

\section{Risk Identification}

Technical Risks. Netflix relies solely on technological infrastructure and an internet connection to deliver its product to consumers around the world. Therefore, any severe and long-lasting power outage would resort to Netflix completely unable to provide its services. This is a risk in all markets that it operates in, especially in the locations that house its servers.

In addition to reaching customers, power outages or other technical faults would inhibit Netflix's ability to produce content, as it would be unable to power its studios and equipment, which would result in potential schedule delays.

Financial Risks. International businesses are susceptible to foreign exchange risks, which falls under financial risks. Being a US-based company reporting its earnings in US dollars, a strong US dollar relative to foreign currencies would negatively impact the company's sales and operating income (Pelts, 2016).

Political Risks. Geopolitical risks, also known as political risks, transpire when a country's government unexpectedly changes its policies, which can negatively affect foreign companies (Beers, 2019). For Netflix, this has a direct impact on the content it can showcase in each country. For example, government censorship requirements can cause Netflix to remove or edit popular content, leading to consumer disappointment, brand tarnishment, or dissatisfaction with the service (Netflix Inc, 2020).

Contractual Risks. Netflix relies on an extensive network of partners to serve its customers across the world. Its partnerships include content providers, as well as cable and telecommunications operators, to make services available through many devices (Netflix Inc, 2020). If such partners were to break the contract or choose not to renew it, this could have adverse effects on Netflix's business. It could mean that Netflix would lose the rights to stream certain content or lose connectivity with its customer base.

Customer Risks. The market for entertainment and content is increasingly competitive. With new and existing competitors, consumers have more options to access entertainment videos. Such competitors may be able to provide compelling content and aggressive pricing, such as AppleTV+ and Disney+ (Babu, 2019). Therefore, if Netflix does not continue its product development or strive to maintain competitiveness in the market, it risks losing its customer base. There is a risk here, given the fact that under the current Netflix's subscription model, there is no cost on the customer side for switching to a new product.

Cost-related Risks. The company typically enters into multi-year commitments with studios and content providers globally, some of which are non-cancelable commitments (Netflix Inc, 2020). Therefore, if global memberships reduce or do not meet the targeted growth, the company's liquidity and revenue would be adversely impacted. Furthermore, as there is more competition in the industry and potentially more demand to secure content from producers and content suppliers, this may drive up the costs of acquiring and producing content.

Human Resources Risks. As of the end of 2019, Netflix had approximately 8,600 fulltime employees globally (Netflix Inc, 2020). In addition to its full-time employees, the company also contracts consultants and third-party service providers. If employees leave to competitors, then there is a risk of Netflix's confidential information being shared with competitors. This is especially impactful if Netflix loses members of its executive team and other key employees. 
Risk Assessment. Tab. 1 illustrates the types of risks with the associated impacts on international business development as well as the possibility of their occurrence.

\section{Table 1 - Risk Classification, Impact and Likelihood \\ (made by the authors)}

\begin{tabular}{|c|c|c|c|}
\hline Risk Type & Brief Explanation & Risk Impact & Risk Likelihood \\
\hline Technical & $\begin{array}{c}\text { Severe technical faults, } \\
\text { power outages and large- } \\
\text { scale/long-lasting internet } \\
\text { connectivity issues. }\end{array}$ & $\begin{array}{l}\text { High - because Netflix's services } \\
\text { rely solely on technology. If there } \\
\text { is a technological failure, it is } \\
\text { unable to provide its service as } \\
\text { such. }\end{array}$ & $\begin{array}{l}\text { Low }(10 \%) \text { - because a large } \\
\text { technological system and } \\
\text { internet usually have backup } \\
\text { systems and servers to prevent } \\
\text { them from long-term outage. }\end{array}$ \\
\hline Financial & $\begin{array}{c}\text { Adverse exchange rate } \\
\text { fluctuations, especially high } \\
\text { USD value, to other } \\
\text { currencies. }\end{array}$ & $\begin{array}{l}\text { Medium - exchange rate } \\
\text { fluctuations are gradual and } \\
\text { typically do not change } \\
\text { drastically. }\end{array}$ & $\begin{array}{l}\text { High( } 100 \%) \text { - exchange rates } \\
\text { typically change daily. }\end{array}$ \\
\hline Political & $\begin{array}{c}\text { Unexpected changes in } \\
\text { local regulations governing } \\
\text { business licensing, allowed } \\
\text { content and government } \\
\text { censorship. }\end{array}$ & $\begin{array}{l}\text { High - changes in regulations } \\
\text { could cause Netflix to discontinue } \\
\text { certain programs, shows, or even } \\
\text { the whole service. }\end{array}$ & $\begin{array}{l}\text { Medium-Low }(30 \%)- \\
\text { regulations concerning media } \\
\text { content are usually set in stone } \\
\text { already, by the time Netflix } \\
\text { enters the country. Further } \\
\text { changes would be relatively rare. }\end{array}$ \\
\hline Contractual & $\begin{array}{l}\text { Global/local content } \\
\text { providers or other key } \\
\text { partners such as cable and } \\
\text { telecommunication } \\
\text { operators decide to } \\
\text { discontinue or break their } \\
\text { contract with Netflix. }\end{array}$ & $\begin{array}{l}\text { High - losing or discontinuing } \\
\text { contracts with key partners could } \\
\text { result in the inability to provide } \\
\text { services or content on certain } \\
\text { markets. }\end{array}$ & $\begin{array}{l}\text { Medium-Low }(40 \%) \text { - such } \\
\text { contracts are typically over an } \\
\text { extended period, and breaking } \\
\text { contracts would result in hefty } \\
\text { penalties. }\end{array}$ \\
\hline Customers & $\begin{array}{l}\text { Customers shift to other } \\
\text { competitor platforms. }\end{array}$ & $\begin{array}{l}\text { Low - if Netflix loses customers, } \\
\text { it will lose revenue. However, } \\
\text { since the fees are relatively low, } \\
\text { when customers leave Netflix, the } \\
\text { impact is low. }\end{array}$ & $\begin{array}{l}\text { Medium-High (60\%) - given } \\
\text { the number of cheaper } \\
\text { alternatives and the economic } \\
\text { downturn, people may switch to } \\
\text { cheaper alternatives. There is } \\
\text { also no switching cost involved. }\end{array}$ \\
\hline Costs & $\begin{array}{l}\text { Suppliers such as content } \\
\text { producers or costs such as } \\
\text { content licenses increase } \\
\text { due to higher bargaining } \\
\text { power on the suppliers' side. }\end{array}$ & $\begin{array}{l}\text { Medium - since suppliers have } \\
\text { higher bargaining power, they } \\
\text { could increase prices, which } \\
\text { would impact costs. }\end{array}$ & $\begin{array}{c}\text { Medium-Low (30\%) - such } \\
\text { contracts are typically over an } \\
\text { extended period, and breaking } \\
\text { contracts would result in hefty } \\
\text { penalties for suppliers. }\end{array}$ \\
\hline $\begin{array}{c}\text { Human } \\
\text { Resources }\end{array}$ & $\begin{array}{l}\text { Turnover of key employees } \\
\text { and movement of employees } \\
\text { (and knowledge) to } \\
\text { competitor companies. }\end{array}$ & $\begin{array}{l}\text { Low - NDAs typically bound } \\
\text { employees upon signing } \\
\text { employment contracts. }\end{array}$ & $\begin{array}{c}\text { Low }(15 \%) \text { - the average } \\
\text { employee turnover rate is } 15 \% \\
\text { annually (Zojceska, 2018) }\end{array}$ \\
\hline
\end{tabular}

The above information is translated into the Impact-Likelihood matrix below (Fig. 3).

Risk Response Development \& Control. Netflix can control potential risks through consistent monitoring and tracking. Many companies now recruit specific resources for risk management. Risk management teams or work groups are dedicated to developing strategies to mitigate the identified risks and apply management methodologies and tools (McConnell, 
2010). Organization-wide training would be also beneficial as it allows everyone within the organization to understand potential risks better.

Then, the employees can help identify potential risks in their workstreams, and by fostering open communication, employees can voice such risks so that the management level or the risk management team is aware and can provide mitigation measures quicker and more efficiently. Also, when relevant trainings are provided, employees can not only understand potential and existing risks but may also prevent such risks from occurring.

\begin{tabular}{|c|c|c|c|c|c|}
\hline & & \multicolumn{4}{|c|}{ Risk Likelihood } \\
\hline & & $\begin{array}{c}\text { High } \\
(80 \% \leq \mathrm{x} \leq 100 \%)\end{array}$ & $\begin{array}{c}\text { Medium-High } \\
(60 \% \leq x \leq 80 \%)\end{array}$ & $\begin{array}{c}\text { Medium-Low } \\
(30 \% \leq x \leq 60 \%)\end{array}$ & $\begin{array}{c}\text { Low } \\
(0 \% \leq x \leq 30 \%) \\
\end{array}$ \\
\hline \multirow{3}{*}{ 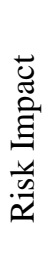 } & High & & & $\begin{array}{l}\text { Political Risks \& } \\
\text { Contractual Risks }\end{array}$ & Technical Risks \\
\hline & Medium & Financial Risks & & Cost Risks & \\
\hline & Low & & CustomerRisks & & $\begin{array}{c}\text { Human Resources } \\
\text { Risks }\end{array}$ \\
\hline
\end{tabular}

Figure 3 - Risks Impacts vs. Likelihood Matrix (made by the authors)

Technical Risks. Netflix can mitigate technical risks. To ensure that the system never goes out or encounters a downtime, the company can install backup servers in different countries and regions. By taking this approach, Netflix can minimize drastic technical errors.

Financial Risks. Netflix can mitigate financial risks by hedging currency risks. By doing this, the company can ensure they maintain a fixed currency exchange rate across different markets they are operating in. This will allow better cost forecasting and planning and would minimize risks against a strengthening US dollar value.

Political Risks. Netflix can avoid political risks by hiring professional resources to carefully study the international markets and regulations before entering a specific market. By doing so, the company can ensure they comply with the local laws and regulations, especially pertaining to censorship, thus avoiding getting sanctioned by local governments.

Contractual Risks. Netflix can mitigate contractual risks by ensuring their contracts are difficult for contract partners to break. They should also negotiate longer terms so that contracted partners are not able to run off to competitor firms, or include non-competition clauses in the contracts specifying which companies the contracted parties are not allowed to contract with, after a certain amount of time from ending the contract with Netflix. This could be an incentive for partners to continue their relationships with Netflix.

Customer Risks. Netflix can either mitigate, or retain customer risks. In mitigation, Netflix could have a fee for customers who prematurely end their membership specified to a certain time. This, however, may make customers become much more reluctant when subscribing in the first place. On the other hand, Netflix can choose to take no actions in changing their packages and accept the related risks, which is ultimately retaining the risk. 
Cost Risks. Netflix can avoid cost risks or suppliers increasing their prices, but ensuring their contracts are legally sound. The contract can include clauses that pertain to suppliers being able to increase their prices to a certain percentage from the original price upon contract renewal.

Human Resources Risks. Netflix can mitigate or retain HR risks. The company can mitigate these risks by ensuring contracts are legally sound, thus preventing employees from disclosing any confidential information to external parties, even when they are not employees any longer. However, such measures can be challenging to monitor and enforce, therefore accepting and retaining the risk is also an option here.

\section{Recommendations}

\section{Expansion into China}

China is an attractive market for many businesses and industries; the video streaming industry is no exception in this regard. With its vast population and economic size, the revenues in the video streaming industry in China are expected to reach $\$ 1,926 \mathrm{mln}$, the second-highest in the world, straight after the United States (Statista, 2020).

Although Netflix is available in over 190 countries, China is still not one of them (Lashinsky, 2017).

Although an attractive market, China is known to be more difficult to enter for other countries, especially media and entertainment companies, given the government's tendency to control the content its consumers see and to promote local players (Lashinsky, 2017).

This is a political risk for Netflix. However, Netflix has slowly introduced its originally produced content in China via a licensing deal with one of China's largest video streaming services, iQiyi.com.

This was Netflix's way of slowly entering China. By doing this, Netflix was able to get a better understanding of Chinese market and indirectly introduce itself to local consumers. Although the partnership with iQiyi.com has ended, there are many other local partners that Netflix could partner with to introduce its content to an even wider audience. For example, Youku and Tencent Video are other large streaming services comparable to iQiyi (Canaves, 2019).

Netflix could also look to partner with companies in parallel industries such as with telecommunication and mobile phone companies like it has done with some other markets. This would give it more exposure and would allow the company to create more ties with local partners, and eventually, government bodies and regulators to pave its way into the market.

For example, in South Korea, Netflix entered into a partnership with a local electronics manufacturer, Samsung. The win-win partnership would allow Netflix to improve its integrations with Samsung devices, whereas Samsung would be able to leverage Netflix's large user base to its advantage (Wood, 2020). Netflix could also take the same approach, for example, by partnering with Huawei, a local technology giant in China.

In order to eventually penetrate the market, Netflix needs to partner, place a greater focus on commissioning locally produced content, and address censorship issues (Kharpal, 2019).

Creating partnerships would help the company to mitigate risks such as political ones, which is the primary risk group when any company is entering Chinese market. It will also 


\section{NETFLIX: A CASE STUDY ON INTERNATIONAL}

need to create content that caters to the needs and interests of Chinese consumers. For example, in South Korea, Netflix has partnered with a rising production studio to produce original content that is attractive for South Korean consumers specifically (Netflix, 2019).

The entrance into China may take time and investment in local content; however, given the potential volume of revenue, it remains a market that has a high potential. This is especially so as competitors at other markets continue to rise as it happened in the U.S., causing Netflix's customer base to slowdown in growth. Therefore, by keeping an eye on Chinese market, Netflix could be the first international video streaming company to enter and benefit exponentially from the first-mover advantage.

\section{Conclusion}

Netflix's rapid international business expansion and the ability to penetrate local markets is an indicator of its success in internationalization. The company's approach to partnering with local companies and localizing its content to each market has provided it with a competitive edge. As a result, the company has captured $183 \mathrm{mln}$ users in over 190 countries (Netflix, n.d).

The video streaming industry remains a competitive business space, especially across international markets, with the rise of global, regional, and local players. Netflix should, therefore, continue to strengthen the already existing partnerships and consider establishing new ones with both global and local companies. This will help the company to mitigate and avoid risks faced at international markets, as well as allow it to maintain competitiveness.

There are also untouched markets with a great potential that Netflix should continue to explore, namely China. Although Netflix has experienced exponential growth over the years with its internationalization strategies, it may start to experience a flatter curve in the future as the market in question matures. Thus, to continue its growth, the company under analysis should look to expand into new markets in the future, especially those that pose great economic returns.

\section{References}

Babu, A. J. (2019. Netflix could lose four million U.S. subscribers in 2020: brokerage. Thomson Reuters. Available online: https://www.reuters.com/article/us-netflix-research-needham/netflixcould-lose-four-million-u-s-subscribers-in-2020-brokerage-idUSKBN1YE1FJ.

Beers, B. (2019). Top Risks for International Business. Investopedia. Available online: https://www.investopedia.com/ask/answers/06/internationalfinancerisks.asp.

Bowman, J. (2017). Netflix has one big weakness. Business Insider. Available online: https://www.businessinsider.com/netflix-has-one-big-weakness-2017-10.

Brenan, L. (2020). How Netflix Expanded to 190 Countries in 7 Years. Harvard Business Review. Available online: https://hbr.org/2018/10/how-netflix-expanded-to-190-countries-in-7-years.

Brodzinsky, S. (2015). Narcos is a hit for Netflix but iffy accents grate on Colombian ears. The Guardian. Available online:https://www.theguardian.com/world/2015/sep/17/narcos-netflixcolombian-accents.

Brooks, R. (2019). The Netflix Guide to World Domination: 5 Localization Strategies to Steal. KInternational. Available online: https://www.k-international.com/blog/netflix-localisationstrategies/. 
Canaves, S. (2019). Understanding China's Video Streaming Services: Part One. China Film Insider. Available online: https://chinafilminsider.com/cbi-video-streaming-part-one/.

Craft (2020). Netflix headquarters and office locations. Craft. Available online: https://craft.co/netflix/locations.

Emster, K.V. (2019). The Economics Driving the Streaming Industry. Berkeley Economic Review. Available online: https://econreview.berkeley.edu/the-economics-driving-the-streamingindustry/.

Investopedia (2020). If You Invested Right After Netflix's IPO (NFLX). Investopedia. Available online: https://www.investopedia.com/insights/how-netflix-makes-money/.

Izquierdo-Castillo, J. (2015). The new media business concept led by Netflix: A study of the model and its projection into the Spanish market. El Profesional de la Informacion. 10.3145/epi.2015.nov.14

Kenton, W. (2019). Business Risk. Investopedia. Available online: https://www.investopedia.com/terms/b/businessrisk.asp.

Kharpal, A. (2019). Netflix has a China strategy - but it doesn't involve launching there soon. CNBC. Available online: https://www.cnbc.com/2019/05/10/netflix-has-a-china-strategy-it-doesntinvolve-launching-there-soon.html.

Kolbin, J. (2019). Netflix's Top 10 Original Movies and TV Shows, According to Netflix. The New York Times. Available online: https://www.nytimes.com/2019/10/17/business/media/netflixtop-ten-movies-tv-shows.html.

Lashinsky, A. (2017). Why Netflix's Move to Enter China Is Both Risky and Relevant. Fortune. Available online: https://fortune.com/2017/04/26/data-sheet-netflix-goes-to-china/.

McBride, S. (2019). Thanks To Netflix, The Biggest Advertising Revolution Has Begun. Forbes. Available online: https://www.forbes.com/sites/stephenmcbride1/2019/12/16/thanks-to-netflixthe-biggest-advertising-revolution-has-begun/?sh=65e1045029f6.

Netflix (2019). CJ ENM/Studio Dragon-Netflix Announce a Long-Term Partnership. Netflix Media Center. Available online: https://about.netflix.com/en/news/cj-enm-studio-dragon-netflixannounce-a-long-term-partnership.

Netflix (2020a). About Netflix. Netflix Media Center. Available online: https://about.netflix.com/en.

Netflix (2020b). Netflix First Quarter 2020 Earnings Interview. Netflix Investors. Available online: https://ir.netflix.net/ir-overview/profile/default.aspx.

Netflix, Inc. (2020c). 2019 10-k form. Available online: https://ir.netflix.net/iroverview/profile/default.aspx.

Pelts, S. (2016). Factors that Could Affect Netflix's Expansion. Yahoo Finance. Available online: https://finance.yahoo.com/news/factors-could-affect-netflix-international-130712152.html.

Penamatsa, V. (2018). Netflix Inc.: A Strategic Analysis. Northeastern University. Available online: https://pdfcoffee.com/netflixstrategyanalysispdf-pdf-free.html.

Pomerantz, D. (2015). Clicking Clean: Which Companies Are Building Us a Green Internet? Greenpeace. Available online: https://www.greenpeace.org/usa/clicking-clean-report/.

Rivera, A. (2019). Netflix SWOT Analysis (Internal \& External Strategic Factors). Rancord. Available online: https://www.rancord.org/netflix-swot-analysis-internal-external-strategicfactors. 


\section{NETFLIX: A CASE STUDY ON INTERNATIONAL}

Reyes, M. S. (2019). Netflix is investing in public policy abroad to enable an international push. Business Insider. Available online: https://www.businessinsider.com/netflix-focuses-on-publicpolicy-strategy-abroad-2019-8.

Saurel, S. (2019). The Netflix Golden Age is Over. Medium. Available online: https://medium.com/swlh/the-netflix-golden-age-is-over-283af995bfba.

Schilling, M. (2015). Netflix In Japan Production Pact With Yoshimoto Kogyo, Say Reports. Variety. Available online: https://variety.com/2015/film/asia/netflix-japan-production-pact-yoshimoto$1201515230 /$.

Smith, D. (2014). Chart of the Day: Netflix's Brilliant Expansion Plan. Business Insider. Available online: https://www.businessinsider.com/chart-of-the-day-netflix-gets-a-huge-boost-frominternational-expansion-2014-9.

Statista (2020). Video Streaming (SVoD). Statista. Available online: https://www.statista.com/outlook/dmo/digital-media/video-on-demand/video-streamingsvod/china\#market-revenue.

Steel, E. (2015). Netflix Accelerates Ambitious Global Expansion as U.S. Growth Slows. The New York Times. Available online: https://www.nytimes.com/2015/01/21/business/media/netflixearnings.html.

The Nation (2017). AIS Partners with Netflix in Thailand. The Nation Thailand. Available online: https://www.nationthailand.com/breakingnews/30307576.

Wood, C. (2020). Netflix has partnered with Samsung to produce content shot on Samsung's Galaxy S20 smartphones. Business Insider. Available online: https://www.businessinsider.com/netflixis-producing-content-exclusive-to-samsung-galaxy-phone-users-2020-2.

Zojceska, A. (2018). HR Metrics: How and Why to Calculate Employee Turnover Rate? TalentLyft. Available online: https://www.talentlyft.com/en/blog/article/242/hr-metrics-how-and-why-tocalculate-employee-turnover-rate.

Paper submitted

Paper accepted for publishing

Paper published online
12 August 2021

20 October 2021

30 November 2021 